\title{
Multidisciplinary management of patent foramen ovale (PFO) and cryptogenic stroke/TIA
}

\author{
This article was published in the following Dove Press journal: \\ Journal of Multidisciplinary Healthcare \\ 12 September 2013 \\ Number of times this article has been viewed
}

\section{Naqibullah Mirzada \\ Per Ladenvall \\ Per-Olof Hansson \\ Peter Eriksson \\ Mikael Dellborg}

GUCH Centre, Sahlgrenska University Hospital/Östra, Gothenburg, Sweden; Dept of Molecular and Clinical Medicine/Cardiology, Institute of Medicine, Sahlgrenska Academy Gothenburg University, Gothenburg, Sweden
Correspondence: Naqibullah Mirzada Department of Internal Medicine, Diagnosvägen II, 41685 Gothenburg, Sweden

$\mathrm{Tel}+463$ I 343807 I

Fax $+4631 \quad 19 \quad 1416$

Email naqibullah.mirzada@vgregion.se
Purpose: Patent foramen ovale (PFO) has been implicated as a risk factor for cryptogenic ischemic stroke (CS). However, there is still a lack of widely accepted, undisputed indications for PFO closure. The present study describes the concept of the multidisciplinary PFO conference and a decision making process for closure versus no closure that was developed into a formalized clinical algorithm, and presents the results of implementing these, in terms of number and proportion of PFO closures as well as repeat referrals.

Design: Five specialists in neurology, cardiology, internal medicine, thromboembolism, and echocardiography evaluated the clinical data of 311 patients at PFO conferences during 2006 to 2009. The main criteria for closure were patients with first-ever CS with PFO and atrial septal aneurysm, or patients with recurrent CS and PFO without atrial septal aneurysm.

Results: A total of 143 patients (46\%) were accepted for closure and 167 patients were rejected. Patients accepted for closure were younger (mean 50 years versus 58 years) $(P<0.001)$. The acceptance rate for PFO closure was similar throughout these years, with an average of $45 \%$. Three of 167 patients (1.8\%) initially rejected for PFO closure were re-referred due to recurrent stroke, and the PFO closure was subsequently performed.

Conclusion: The acceptance rate of less than $50 \%$ in the present study underscores the complex relationship between CS and PFO. Whatever the criteria used for PFO closure, any unit caring for these patients needs to have a rigorous process to avoid overtreatment as well as undertreatment and to ensure that personal preferences and economic incentives do not steer the selection process. Our algorithm provides a stable acceptance rate and a low rate of repeat referrals.

Keywords: patent foramen ovale, cryptogenic stroke, clinical algorithm, patent foramen ovale closure

\section{Introduction}

Cryptogenic ischemic stroke (CS) is defined as a stroke that cannot be attributed to any specific cause after an extensive search for the most common ones, such as cardiac emboli, or large or small vessel disease. It is present in about $25 \%$ of ischemic stroke patients below 70 years. ${ }^{1}$

Patent foramen ovale (PFO) has been implicated as a risk factor for CS, due to paradoxical embolism. A few studies have reported a significantly higher prevalence of PFO in patients with CS than in normal controls (44\%-66\% versus $0 \%-27 \%){ }^{2-5}$ The reported annual recurrence rate in patients with PFO and CS ranges from $3.8 \%$ to $16 \%$, indicating the need for prevention. ${ }^{6-12}$ During the last decades, the therapeutic measures that have been introduced for prevention of recurrent cerebrovascular events in patients with PFO and CS are long-term anticoagulation or antiplatelet medication, 
surgical closure, and transcatheter closure. The observational data examining outcomes have been very promising. When studying the five largest observational trials, we found a pooled effect indicating that PFO closure by device lowers the relative risk for recurrent cerebrovascular events by almost $80 \%{ }^{13-17}$ Many randomized trials in this field have been started, ${ }^{18}$ and to date, three randomized trials have been published. ${ }^{19-21}$ Yet, widely accepted indications are lacking, and in the clinical setting, there are difficulties in defining whether CS is present or not. Given these ambiguities, which are compounded by the increasing number of cases and the complexity of CS, there is a real risk of variation in clinical decision making between doctors. Consequently, to address this, we have formalized a multidisciplinary approach using a dedicated PFO conference involving experts in interventional cardiology, neurology, internal medicine, cardiac imaging, thromboembolism, and cardiology. Since 1997, the Gothenburg Center for Grown-Up Congenital Heart Disease (GUCH) has performed percutaneous closure of PFO, in order to reduce the risk of recurrent stroke in selected patients.

The present study describes the concept of the multidisciplinary PFO conference and the process for making closure versus no closure decisions that was developed into a formalized clinical algorithm, and presents the results of implementing these, in terms of number and proportion of PFO closures, as well as repeat referrals.

\section{Material and methods Patient selection}

The present study included 311 consecutive patients with cerebrovascular events (including transient ischemic attack [TIA] and ischemic strokes) and a PFO, referred to our GUCH unit, Sahlgrenska University Hospital/Östra, during the period between January 2006 and December 2009. Patients who were referred because of decompression illness, platypnea-orthodeoxia, or migraine headache were excluded. The patients were referred from hospitals all over Sweden but mainly from the western and central parts of the country. The GUCH unit at our hospital is a tertiary center, serving a population of approximately three million. The present study was approved by the regional ethics review board in Gothenburg. Patients were informed by referring physicians and agreed to participate in this study.

The main criteria for closure were patients with a firstever CS with high-risk morphology (PFO with atrial septal aneurysm) or recurrent $\mathrm{CS}$ and a PFO with or without atrial septal aneurysm (high- or low-risk morphology).
Recurrent stroke was defined as either more than one clinical event of ischemic stroke, or at least one clinical event of stroke and multiple ischemic brain lesions, of different ages, on a computed tomography (CT) scan or magnetic resonance imaging (MRI) scan of the brain. All patients who were considered for PFO closure had a transesophageal echocardiography (TEE)-verified right-to-left shunting at rest or under Valsalva maneuver.

\section{The diagnostic workup to verify ischemic stroke or TIA in these patients occurred in two stages}

In the first stage, the diagnosis of ischemic stroke or TIA was made by the stroke team at the neurological or stroke medicine unit of the hospital where the patient had been admitted for an index event. The stroke team consisted of neurologists or internal medicine specialists working with stroke medicine, specialist stroke nurses, physiotherapists, occupational therapists, psychologists, and other members of the multidisciplinary team. All patients had a clinical diagnosis of CS (that is, an identifiable cause of an ischemic cerebral stroke was not found) before they were referred to our GUCH unit. In order not to miss any information about patients at the time of conference, we asked the referring medical staff to fill in the PFO questionnaire, which gathers factual information about patients' demographic data, the investigation process for the diagnosis of CS, such as CT scan and MRI of the brain and vertebral circulation, carotid Doppler, serum lipids, presence of thrombophilia, medical treatment, and other concomitant diseases.

The PFO questionnaire is in Swedish and is available at our website, http://www.guch.nu/guch\%20hemsida/Gbg/ information lakare/PFO konferensunderlag.pdf.

In the second stage, PFO conferences were held twice a month at our GUCH unit, in which five specialists in neurology, cardiology, internal medicine, thromboembolism, and echocardiography met to discuss patients' data, including medical records, TEE, CT scans, and MRI of the brain. The stroke etiology and morphological risk were evaluated for each patient. Decisions were made by consensus (Figure 1).

\section{Implementation of treatment}

Closure of the PFO, guided by a perioperative TEE, was performed under general anesthesia. All patients were taking warfarin or antiplatelet therapy before closure and received intravenous prophylactic antibiotics during the procedure; they were given a loading dose of $160 \mathrm{mg}$ aspirin or $300 \mathrm{mg}$ 


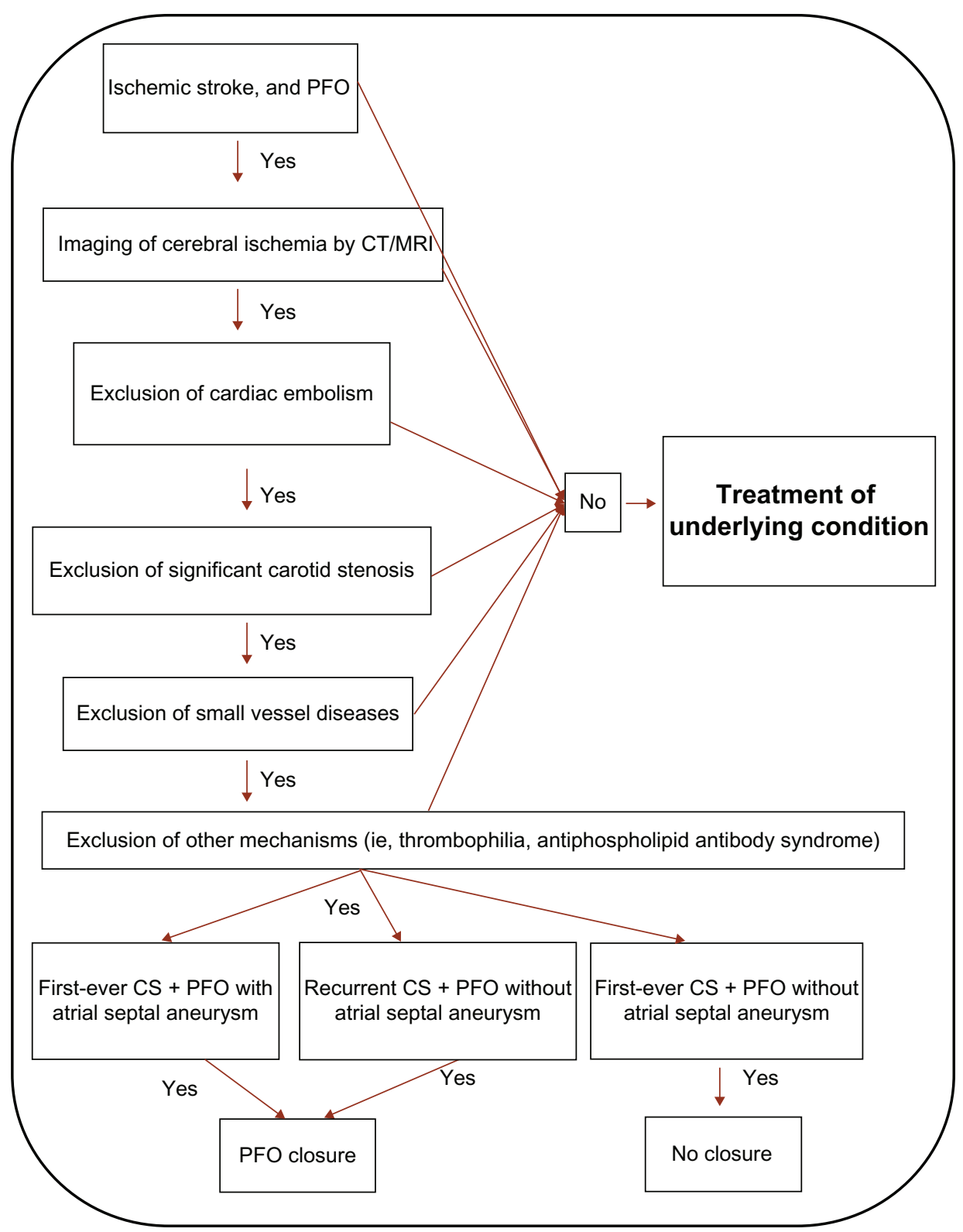

Figure I Clinical algorithm for a multidisciplinary decision on PFO closure, in patients with cryptogenic stroke.

Abbreviations: CS, cryptogenic ischemic stroke; CT, computed tomography; MRI, magnetic resonance imaging; PFO, patent foramen ovale.

clopidogrel and low-molecular-weight heparin. The PFO was visualized and its size was measured both by balloon sizing and TEE. The device was chosen according to the balloon size of the PFO.

The vast majority of closures used an Amplatzer ${ }^{\circledR}$ PFO Occluder device (AGA Medical Corp, Plymouth, MN, USA). If the PFO size was more than $15 \mathrm{~mm}$, an Amplatzer Septal Occluder (atrial septal defect [ASD] closure device) or an Amplatzer Multi-Fenestrated Septal Occluder "Cribriform" (multi-fenestrated ASD closure device) could be used; if it was less than $7 \mathrm{~mm}$, a BioSTAR ${ }^{\circledR}$ (NMT Medical, Inc., Boston, MA, USA), a Solysafe ${ }^{\circledR}$ Septal Occluder (Swissimplant
AG, Solothurn, Switzerland), or a GORE ${ }^{\circledR}$ HELEX $^{\circledR}$ Septal Occluder (WL Gore and Assoc, Inc, Newark, DE, USA) device could be considered, at the operator's discretion. Patients were monitored by telemetry (continuous 12-lead electrocardiogram [ECG]) during the next 24 hours after closure. The day after the closure, a transthoracic echocardiogram was repeated to confirm proper position of the device and exclude leakage, whereupon the patient was discharged.

\section{Transesophageal echocardiography}

TEE is considered the method of choice for PFO detection. ${ }^{22}$ All patients were investigated with TEE before they were 
referred to us. PFO was diagnosed if contrast bubbles entered the left atrium through the oval structure or if color Doppler detected right-to-left flow between the two septa. Agitated $\mathrm{NaCl}$ solution, mixed with $5 \%-10 \%$ air by repeated and forceful injection from one syringe to another through a three-way stopcock, was used as a contrast medium. A PFO was defined as the appearance of microbubbles in the left atrium within three heartbeats from when the contrast filled the right atrium, in the absence of a tissue defect. ${ }^{23}$ It is important to mention that a PFO is functionally closed most of the time, due to higher left than right atrial pressure. A provocation, such as the Valsalva maneuver, may be used in order to invert the interatrial pressure gradient and thus open the PFO. Rightto-left shunting, at rest or during the Valsalva maneuver, was detected in all patients by TEE before the PFO conferences.

Statistical analyses were performed using PASW Statistics for Windows, Version 18.0 software (IBM Corporation, Armonk, NY, USA). Variables were compared using Pearson chi-square test, and $P<0.05$ was considered to be a significant difference between groups.

\section{Results}

In total, 311 patients were evaluated at the PFO conferences. We accepted 144 patients for PFO closure (99 men and 45 women), whereas 167 patients were rejected (93 men and 74 women). Our acceptance rate for closure was similar throughout these years, with an average of $45 \%$ (43\% in $2006,42 \%$ in $2007,52 \%$ in 2008 , and $42 \%$ in 2009 ). Patients accepted for closure were younger (mean 50 years versus 58 years $)(P<0.001)$. The mean age for men was 51 years and for women was 47 years in the closure group versus 57 years for men and 59 years for women in the group that was rejected for PFO closure. Of the patients in the closure group, 84\% were under 60 years and 94\% were under 65 years. As shown in Table 1, the presence of risk factors, such as smoking, diabetes, hyperlipidemia, and hypertension, was slightly higher in the rejected group. One patient with atrial fibrillation was accepted for closure due to epilepsy and contraindication to warfarin. This patient had already had several recurrent strokes when referred to us (Table 1).

\section{Inclusion criteria for closure}

The most common criterion for closure was a first-ever stroke with high-risk morphology (PFO with atrial septal aneurysm) or a recurrent CS with a low-risk morphology (PFO without atrial septal aneurysm). Our criteria for PFO closure also included patients with one CS and another thromboembolic risk factor, in this case activated protein $\mathrm{C}$
Table I Baseline characteristics of patients referred to the PFO conference

\begin{tabular}{|c|c|c|c|}
\hline Characteristics & $\begin{array}{l}\text { Accepted } \\
\text { for closure } \\
N=144(\%)\end{array}$ & $\begin{array}{l}\text { Rejected } \\
\text { for closure } \\
N=167(\%)\end{array}$ & P-value* \\
\hline Age, years & 50 & 58 & $<0.001$ \\
\hline Men & $99(69)$ & $93(56)$ & $<0.05$ \\
\hline Women & $45(3 I)$ & $74(44)$ & $<0.05$ \\
\hline First-ever stroke/TIA & $95(66)$ & $10 I(6 I)$ & NS \\
\hline Hypertension & $27(19)$ & $61(36)$ & 0.01 \\
\hline Hyperlipidemia & $23(16)$ & $44(26)$ & 0.08 \\
\hline Diabetes mellitus & $3(2)$ & $16(10)$ & $<0.01$ \\
\hline Atrial fibrillation & $\mathrm{I}(0.7)$ & $15(9)$ & $<0.01$ \\
\hline $\mathrm{MI}<4$ weeks & 0 & I $(0.6)$ & NS \\
\hline Carotid stenosis $>50 \%$ & 0 & $9(5)$ & $<0.001$ \\
\hline Smoking & $13(9)$ & $30(18)$ & 0.15 \\
\hline
\end{tabular}

Notes: *Chi-square statistic for difference in proportion between the accepted and rejected groups.

Abbreviations: MI, myocardial infarction; NS, not significant; PFO, patent foramen ovale; TIA, transient ischemic attack.

(APC) resistance, and patients with CS with a low-risk but very large PFO, indicated by massive right-to-left passage of more than 20 bubbles, without atrial septal aneurysm. Two patients with only one CS and low risk for PFO were accepted for device closure for other reasons.

The following types of devices were used for PFO closure in the 144 patients: Amplatzer Septal Occluder device in 98 patients, BioSTAR ${ }^{\circledR}$ (NMT Medical, Inc.) in 30 patients, the GORE HELEX Septal Occluder in two patients, the Solysafe Septal Occluder in four patients, the Amplatzer ASD Cribriform Occluder in ten patients. The mean balloon size of the PFO, as measured by TEE, was 9.25 millimeters (ranging $2 \mathrm{~mm}-24 \mathrm{~mm}$, with a standard deviation of $4.58 \mathrm{~mm}$ ).

\section{Patients rejected for PFO device closure}

In 167 of the referred patients, we did not find an indication to perform PFO closure, when adopting the criteria described above. The most common reason to refrain from closure was that the multidisciplinary panel did not regard the stroke as cryptogenic, and the second most common reason was the occurrence of only one stroke in patients with PFO with lowrisk morphology. Three patients were initially rejected for PFO closure and given medical treatment instead but were referred again after a second cerebrovascular event and were then accepted for closure. The criteria for acceptance and rejection for PFO closure are shown in Table 2.

\section{Discussion}

The relationship between PFO and stroke is not straightforward. PFO is not a risk factor for stroke per se, but for CS in particular. This makes it pivotal that only CS patients are 
Table 2 Outcome of PFO conferences, criteria for closure or rejection

\begin{tabular}{|c|c|c|}
\hline Criteria & Number & $\begin{array}{l}\% \text { (of all } \\
\text { referrals) }\end{array}$ \\
\hline \multicolumn{3}{|l|}{ Panel A: accepted for closure } \\
\hline Cryptogenic stroke + high risk PFO & 92 & $30 \%$ \\
\hline $\begin{array}{l}\text { Recurrent cryptogenic stroke }+ \text { low } \\
\text { risk PFO }\end{array}$ & 42 & $14 \%$ \\
\hline $\begin{array}{l}\text { First-ever cryptogenic stroke }+ \text { other } \\
\text { thromboembolic risk factors }\end{array}$ & 4 & $1 \%$ \\
\hline $\begin{array}{l}\text { First-ever cryptogenic stroke + low risk } \\
\text { PFO but massive right-to-left passage }\end{array}$ & 4 & $1 \%$ \\
\hline $\begin{array}{l}\text { First-ever cryptogenic stroke + low } \\
\text { risk PFO }\end{array}$ & 2 & $<1 \%$ \\
\hline Patients accepted, all criteria & 144 & $46 \%$ \\
\hline \multicolumn{3}{|l|}{ Panel B: rejected for closure } \\
\hline Not stroke/TIA & 14 & $5 \%$ \\
\hline Not cryptogenic stroke & 76 & $24 \%$ \\
\hline $\begin{array}{l}\text { First ever cryptogenic stroke }+ \\
\text { low risk PFO, not recurrent }\end{array}$ & 39 & $13 \%$ \\
\hline Continuous warfarin indication & 13 & $4 \%$ \\
\hline Other reason & 15 & $5 \%$ \\
\hline $\begin{array}{l}\text { Incomplete investigation, decision } \\
\text { not possible }\end{array}$ & 10 & $3 \%$ \\
\hline Patients not accepted, all criteria & 167 & $54 \%$ \\
\hline Total & 311 & $100 \%$ \\
\hline
\end{tabular}

Notes: Other reasons were age $>75$ years and malignancy. High-risk PFO $=$ PFO with atrial septal aneurysm; low-risk PFO = PFO without atrial septal aneurysm; other thromboembolic risk factor $=$ APC resistance.

Abbreviations: APC, activated protein C; PFO, patent foramen ovale; TIA, transient ischemic attack.

treated with closure of their PFO, as the other patients have a known etiology for their stroke, and their risk of stroke recurrence is thus unaffected by PFO closure. CS is a diagnosis of exclusion, which is dependent on the thoroughness of the clinical investigation. In $44 \%$ to $66 \%$ of patients with CS, diagnostic workup reveals a $\mathrm{PFO},{ }^{4,24,25}$ and an association between PFO and CS has been described in observational clinical trials. ${ }^{26,27}$ Patients with documented PFO and previous embolic events are at an increased risk, of up to $4.2 \%$ per year, for recurrent stroke, even in the context of therapeutic anticoagulation. ${ }^{9,28,29}$ Patients with PFO and atrial septal aneurysm are at higher risk of recurrent stroke than those with PFO alone. ${ }^{11}$ Transcatheter treatment of atrial septal aneurysm and PFO is reported to be safe and effective in patients with paradoxical embolism. ${ }^{30}$

We established PFO conferences to create a balanced view of decision making by involving experts from different relevant fields and to avoid leaving the decision to the interventionist or neurologist alone. We have developed an algorithm to facilitate the diagnostic workup (Figure 1). This algorithm is based on evidence from the literature and from clinical decision-making on our patients since 1997.
At the PFO conference, the specialists in internal medicine and neurology assess whether the neurological symptoms were related to a stroke and whether other etiologies can be ruled out and thus, whether the stroke can be diagnosed as cryptogenic. The interventional cardiologist and specialist in echocardiography assess whether the PFO is suitable for closure and whether the TEE provides enough information to distinguish high risk from low risk PFO. Other concomitant disease that may influence the treatment of the individual patient is also taken into consideration.

The patients who were accepted for PFO closure were younger than those who were recommended medical treatment only. Since other etiologies, namely large-vessel atherosclerosis, small-artery disease, and cardiac embolism, are more frequent in the elderly, the diagnosis of CS is less frequent than in the young. In addition, the association of PFO with CS has consistently been reported in patients younger than 55 years, whereas the association in those older than 55 years remains uncertain. ${ }^{27}$ Among our patients in the closure group, $72 \%$ were younger than 55 years. Of those older than 55 years, $28 \%$ were judged to have PFO and CS and therefore were considered for closure. ${ }^{31}$

Regarding sex, we accepted fewer women than men (31\% versus $69 \%$ ), and moreover, fewer women were referred. Women were older, but did not differ in the proportion of risk factors (data not shown). A trend of less prevalent previous cerebrovascular disease among women, as compared with men, was also observed (chi-square $P=0.052$ ). The observed difference in this retrospective analysis could have been caused by selection bias, but further study, to investigate this putative sex difference, is warranted.

Although device closure of PFO has increasingly been performed since the early 1990 s, there is still not sufficient evidence to establish that device closure is more efficient than medical treatment. On the one hand, the first randomized trial to be published concluded that percutaneous closure of PFO with the STARFlex device (NMT Medical, Inc.) plus medical therapy did not offer any significant benefit over medical therapy alone for the prevention of recurrent stroke or TIA, in patients younger than 60 years presenting with CS or TIA and a PFO. ${ }^{19}$

On the other hand, by pooling the results of the five largest observational trials, we found a relatively large effect indicating that PFO closure by device lowers the relative risk for recurrent cerebrovascular events. ${ }^{13-17}$

One previous study reported the use of multidisciplinary management of $\mathrm{PFO}$ and $\mathrm{CS}$, but it included fewer patients and was conducted under a shorter time period. ${ }^{32}$ 
In the setting of multiple treatment options, unclear evidence, the complexity of CS, as well as the difficulty, in the clinical setting, of defining whether CS is present or not, a multidisciplinary approach may enhance the stability of clinical decision making and improve quality of care. It maintains transparency and clarity of medical decision making, which is important for both patients and payers of health care. The regular PFO conferences may also promote adherence to the decision algorithm for how to exclude and include PFO patients with stroke or TIA for closure. We performed approximately the same proportion of closures over all years monitored, and we have a low rate of repeat referrals.

The results of this study should be considered in the light of the following limitations. Firstly, the diagnosis of paradoxical embolism remains presumptive and cannot be considered synonymous with CS or TIA. Secondly, the patient population in this study was a selected group referred to our hospital in a nonrandomized, retrospective, consecutive order, which may not be the case in other published studies.

In conclusion, less than $50 \%$ of referred cases with PFO and suspected CS fulfilled our acceptance criteria for closure. The acceptance rates were constant through this period. Three patients were initially rejected for closure and given medical treatment instead but were referred again after a second cerebrovascular event and were then accepted for closure. Our currently used algorithm seems to have given a low rate of misclassification, of below $1.8 \%$. In view of the $1 \%-2 \%$ rate of severe periprocedural complications in most published series, this misclassification rate does not seem unreasonable. We believe that a standardized multidisciplinary approach and a clinical algorithm, as described in this paper, are important for the proper assessment of PFO as a risk factor for CS.

\section{Acknowledgments}

The present study was supported by the Swedish Society of Medicine, and by grants from the Swedish state (under the LUA/ALF agreement) and from the Region Västra Götaland.

The authors thank research assistants Görel HultsbergOlsson and Helena Svensson for excellent assistance throughout the study. We also acknowledge the secretarial assistance from Eva Thydén.

\section{Disclosure}

The authors report no conflicts of interest in this work.

\section{References}

1. Jood K, Ladenvall C, Rosengren A, Blomstrand C, Jern C. Family history in ischemic stroke before 70 years of age: the Sahlgrenska Academy Study on Ischemic Stroke. Stroke. 2005;36(7):1383-1387.

2. Hagen PT, Scholz DG, Edwards WD. Incidence and size of patent foramen ovale during the first 10 decades of life: an autopsy study of 965 normal hearts. Mayo Clin Proc. 1984;59(1):17-20.

3. Lechat P, Mas JL, Lascault G, et al. Prevalence of patent foramen ovale in patients with stroke. $N$ Engl J Med. 1988;318(18):1148-1152.

4. Webster MW, Chancellor AM, Smith HJ, et al. Patent foramen ovale in young stroke patients. Lancet. 1988;2(8601):11-12.

5. Wu LA, Malouf JF, Dearani JA, et al. Patent foramen ovale in cryptogenic stroke: current understanding and management options. Arch Intern Med. 2004;164(9):950-956.

6. Bogousslavsky J, Garazi S, Jeanrenaud X, Aebischer N, Van Melle G. Stroke recurrence in patients with patent foramen ovale: the Lausanne Study. Lausanne Stroke with Paradoxal Embolism Study Group. Neurology. 1996;46(5):1301-1305.

7. Comess KA, DeRook FA, Beach KW, Lytle NJ, Golby AJ, Albers GW. Transesophageal echocardiography and carotid ultrasound in patients with cerebral ischemia: prevalence of findings and recurrent stroke risk. J Am Coll Cardiol. 1994;23(7):1598-1603.

8. Cujec B, Mainra R, Johnson DH. Prevention of recurrent cerebral ischemic events in patients with patent foramen ovale and cryptogenic strokes or transient ischemic attacks. Can J Cardiol. 1999;15(1):57-64.

9. Hanna JP, Sun JP, Furlan AJ, Stewart WJ, Sila CA, Tan M. Patent foramen ovale and brain infarct. Echocardiographic predictors, recurrence, and prevention. Stroke. 1994;25(4):782-786.

10. Homma S, Sacco RL, Di Tullio MR, Sciacca RR, Mohr JP; PFO in Cryptogenic Stroke Study (PICSS) Investigators. Effect of medical treatment in stroke patients with patent foramen ovale: patent foramen ovale in Cryptogenic Stroke Study. Circulation. 2002;105(22):2625-2631.

11. Mas JL, Arquizan C, Lamy C, et al; Patent Foramen Ovale and Atrial Septal Aneurysm Study Group. Recurrent cerebrovascular events associated with patent foramen ovale, atrial septal aneurysm, or both. N Engl J Med. 2001;345(24):1740-1746.

12. Paciaroni M, Agnelli G, Bertolini A, et al; FORI (Foramen Ovale Registro Italiano) Investigators. Risk of recurrent cerebrovascular events in patients with cryptogenic stroke or transient ischemic attack and patent foramen ovale: the FORI (Foramen Ovale Registro Italiano) study. Cerebrovasc Dis. 2011;31(2):109-116.

13. Harrer JU, Wessels T, Franke A, Lucas S, Berlit P, Klötzsch C. Stroke recurrence and its prevention in patients with patent foramen ovale. Can J Neurol Sci. 2006;33(1):39-47.

14. Schuchlenz HW, Weihs W, Berghold A, Lechner A, Schmidt R. Secondary prevention after cryptogenic cerebrovascular events in patients with patent foramen ovale. Int J Cardiol. 2005;101(1):77-82.

15. Thanopoulos BV, Dardas PD, Karanasios E, Mezilis N. Transcatheter closure versus medical therapy of patent foramen ovale and cryptogenic stroke. Catheter Cardiovasc Interv. 2006;68(5):741-746.

16. Weimar C, Holle DN, Benemann J, et al; German Stroke Study Collaboration. Current management and risk of recurrent stroke in cerebrovascular patients with right-to-left cardiac shunt. Cerebrovasc Dis. 2009;28(4):349-356.

17. Windecker S, Wahl A, Nedeltchev K, et al. Comparison of medical treatment with percutaneous closure of patent foramen ovale in patients with cryptogenic stroke. J Am Coll Cardiol. 2004;44(4):750-758.

18. O'Gara PT, Messe SR, Tuzcu EM, Catha G, Ring JC; American Heart Association; American Stroke Association; American College of Cardiology Foundation. Percutaneous device closure of patent foramen ovale for secondary stroke prevention: a call for completion of randomized clinical trials: a science advisory from the American Heart Association/ American Stroke Association and the American College of Cardiology Foundation. Circulation. 2009;119(20):2743-2747.

19. Furlan AJ, Reisman M, Massaro J, et al. Closure or medical therapy for cryptogenic stroke with patent foramen ovale. New Engl J Med. 2012;366(11):991-999. 
20. Meier B, Kalesan B, Mattle HP, et al; PC Trial Investigators. Percutaneous closure of patent foramen ovale in cryptogenic embolism. NEngl J Med 2013;368(12):1083-1091.

21. Carroll JD, Saver JL, Thaler DE, et al; RESPECT Investigators. Closure of patent foramen ovale versus medical therapy after cryptogenic stroke. N Engl J Med. 2013;368(12):1092-1100.

22. Siostrzonek P, Lang W, Zangeneh M, et al. Significance of left-sided heart disease for the detection of patent foramen ovale by transesophageal contrast echocardiography. J Am Coll Cardiol. 1992;19(6): 1192-1196.

23. Johansson MC, Eriksson P, Peker Y, Hedner J, Råstam L, Lindblad U. The influence of patent foramen ovale on oxygen desaturation in obstructive sleep apnoea. Eur Respir J. 2007;29(1):149-155.

24. Job FP, Ringelstein EB, Grafen Y, et al. Comparison of transcranial contrast Doppler sonography and transesophageal contrast echocardiography for the detection of patent foramen ovale in young stroke patients. Am J Cardiol. 1994;74(4):381-384.

25. Steiner MM, Di Tullio MR, Rundek T, et al. Patent foramen ovale size and embolic brain imaging findings among patients with ischemic stroke. Stroke. 1998;29(5):944-948.

26. Di Tullio M, Sacco RL, Gopal A, Mohr JP, Homma S. Patent foramen ovale as a risk factor for cryptogenic stroke. Ann Intern Med. 1992; 117(6):461-465
27. Overell JR, Bone I, Lees KR. Interatrial septal abnormalities and stroke: a meta-analysis of case-control studies. Neurology. 2000;55(8): 1172-1179.

28. Chatterjee $\mathrm{T}$, Petzsch $\mathrm{M}$, Ince $\mathrm{H}$, et al. Interventional closure with Amplatzer PFO occluder of patent foramen ovale in patients with paradoxical cerebral embolism. J Interv Cardiol. 2005;18(3):173-179.

29. De Castro S, Cartoni D, Fiorelli M, et al. Morphological and functional characteristics of patent foramen ovale and their embolic implications. Stroke. 2000;31(10):2407-2413.

30. Wahl A, Krumsdorf U, Meier B, et al. Transcatheter treatment of atrial septal aneurysm associated with patent foramen ovale for prevention of recurrent paradoxical embolism in high-risk patients. $J$ Am Coll Cardiol. 2005;45(3):377-380.

31. Handke M, Harloff A, Olschewski M, Hetzel A, Geibel A. Patent foramen ovale and cryptogenic stroke in older patients. New Engl J Med. 2007;357(22):2262-2268.

32. Rigatelli G, Braggion G, Chinaglia M, et al. Setting up a multidisciplinary program for management of patent foramen ovale-mediated syndromes. J Interv Cardiol. 2006;19(3):264-268.
Journal of Multidisciplinary Healthcare

\section{Publish your work in this journal}

The Journal of Multidisciplinary Healthcare is an international, peerreviewed open-access journal that aims to represent and publish research in healthcare areas delivered by practitioners of different disciplines. This includes studies and reviews conducted by multidisciplinary teams as well as research which evaluates the results or conduct of such teams or health-

\section{Dovepress}

care processes in general. The journal covers a wide range of areas and welcomes submission from practitioners at all levels, from all over the world. The manuscript management system is completely online and includes a very quick and fair peer-review system. Visit http://www.dovepress. com/testimonials.php to read real quotes from published authors. 